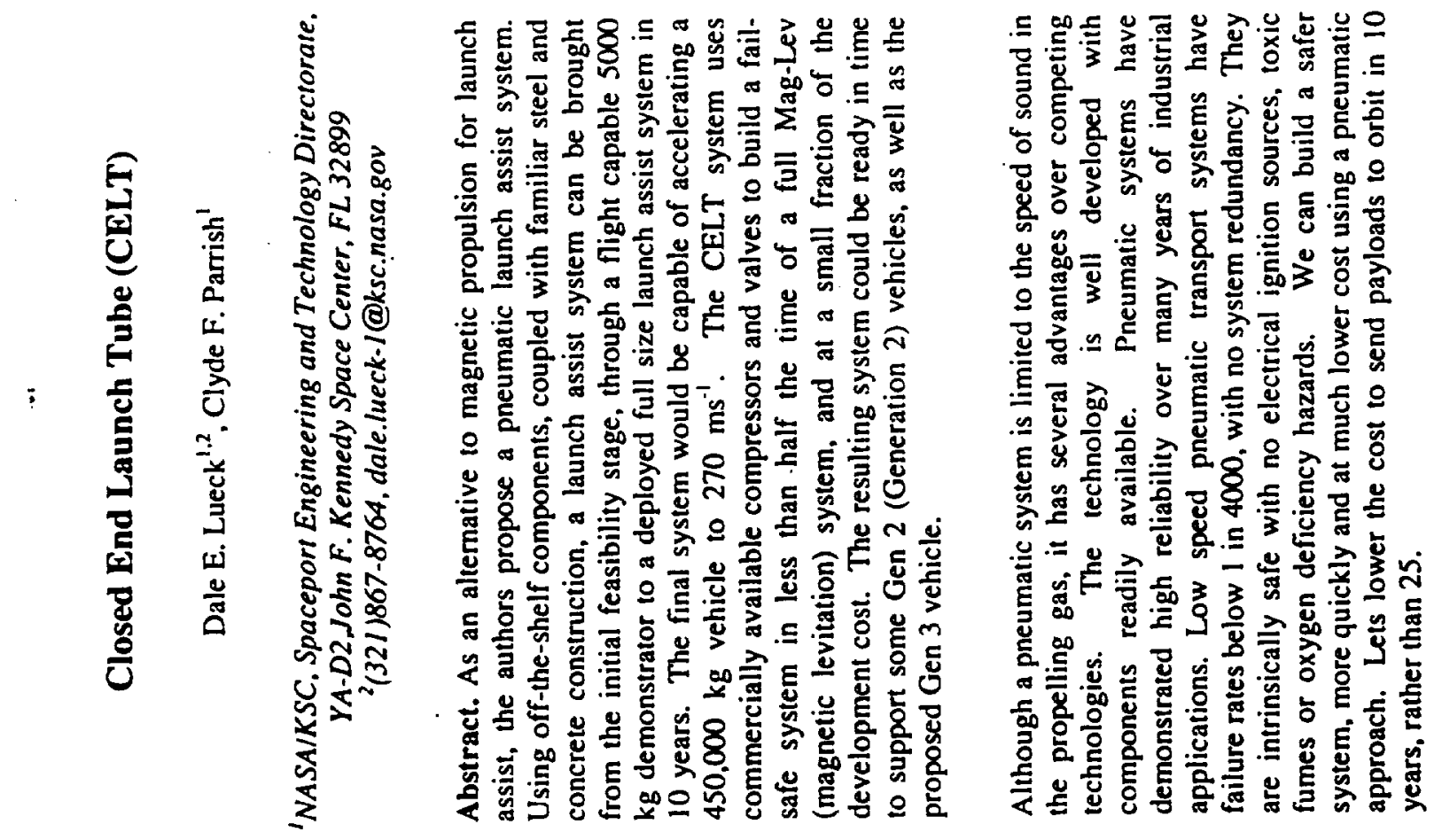




\title{
Closed End Launch Tube (CELT)
}

\author{
Dale E. Lueck ${ }^{1,2}$, Clyde F. Parrish ${ }^{1}$ \\ 'NASAIKSC, Spaceport Engineering and Technology Directorate, YA-D2, John F. Kennedy Space Center, FL 32899 \\ 2(321)867-8764, dale.lueck.1@ksc.nasa.gov
}

\begin{abstract}
As an altemative to magnetic propulsion for launch assist, the authors propose a pneumatic launch assist system. Using off-the-shelf components, coupled with familiar steel and concrete construction, a launch assist system can be brought from the initial feasibility stage, through a flight capable $5000 \mathrm{~kg}$ demonstrator to a deployed full size launch assist system in 10 years. The final system would be capable of accelerating a $450,000 \mathrm{~kg}$ vehicle to $270 \mathrm{~ms}^{-1}$. The CELT system uses commercially available compressors and valves to build a fail-safe system in less than half the time of a full Mag-Lev (magnetic levitation) system, and at a small fraction of the development cost. The resulting system could be ready in time to support some Gen 2 (Generation 2) vehicles, as well as the proposed Gen 3 vehicle.
\end{abstract}

\section{BACKGROUND}

The currently proposed Generation 3 vehicle uses a combined cycle engine that operates in the RAM-jet, SCRAM, or rocket mode as conditions require. It saves on vehicle weight by utilizing air as the oxidizer until high altitude and speed are attained, and only then switching into rocket mode with carried LOX (liquid oxygen) as the oxidizer. Since the weight of oxygen carried can vary from 3.4 to 8 times the weight of the fuel, much of the vehicle weight can be eliminated by utilizing air as the oxidant. The RAM jet engine requires quite high velocities to achieve initial takeoff thrust, and the use of a launch assist system to achieve an initial speed of $270 \mathrm{~ms}^{-1}$ or higher can further reduce vehicle takeoff weight. A Mag-Lev system using magnetic levitation and magnetic propulsion to accelerate a sled carrying a $450 \mathrm{MT}$ vehicle to this speed is the currently base lined technology.

\section{Mag-Lev Engineering Challenges}

While Mag-Lev has been demonstrated in low weight systems and to speeds well above the required $270 \mathrm{~ms}^{-1}$, there are some serious challenges to be overcome in a Gen 3 vehicle launch assist system. The large weight requires enormous amounts of energy to be released in the 10-20 seconds that the vehicle is being accelerated. These needs can be met in a $5000 \mathrm{~kg}$ weight class vehicle using state-of-the-art flywheel assemblies for the power source. A dozen or more such assemblies spread along the track and connected to super conducting magnets with high power electronic switching will tax current technological capabilities. Multiply the weight by 100 for a full scale system, and you are well beyond current capabilities. A 25 year plan of development is planned to overcome the technical hurdles and deploy an operational $450,000 \mathrm{~kg}$ launch assist system based on this technology. In the mean time, the launch community will not be able to take advantage of the much lower launch costs of such a system. We felt there might be a faster and cheaper way to obtain the desired launch assist in a more timely fashion, and began exploring ways to achieve the same goal with existing technology.

\section{Pneumatic Trains}

Armed with a vague memory of a much earlier pneumatic transport system for people, we found the following (slightly modified) quote in a small article posted by Scientific American on their web site: 
"In 1870 Alfred Ely Beach... financed the construction of a prototype subway in New York Ciry. Based on experimental European pneumatic trains, it consisted of a block-long stretch of tunnel through which a cylindrical car was pushed and pulled by a huge fan. Though popular, this system failed to win over the municipal authorities. who later built elevated trains instead.

But the idea of using air pressure to propel a train never lost its appeal. In the mid-1960s Lockheed, MIT, and the U.S. Department of Commerce, contemplated the feasibility of pneumatic trains connecting cities along the Bostonto-Washington corridor."

Armed with this knowledge, we quickly uncovered many articles and reports on the proposed Tube Vehicle System (TVS) for the northeast corridor. Several of these are listed in the references for those who wish to delve more deeply into the subject. What is most interesting about the proposal and subsequent studies is not that it was rejected as unfeasible (it was), but that the reasons for that rejection do not apply to a much smaller launch assist system required for Gen 2 or Gen 3 vehicles. The weight of the proposed trains would have exceeded that of a Gen 3 vehicle, and was comparable to the proposed moving mass of vehicle, sled and piston in the present proposal $(700,000 \mathrm{~kg})$. The design speed of the trains would have been $220 \mathrm{~ms}^{-1}$, within reach of the desired $270 \mathrm{~ms}^{-1}$ in the present proposal. The major problems with the TVS proposal was the boring of large tunnels several hundred feet underground for hundreds of kilometers and keeping them evacuated. Any substantial break in the vacuum system would strand the passengers and train with little hope of quick recovery. Knowing that our system would only be 6 $\mathrm{km}$ long, and might be able to operate without a vacuum ahead of the piston, we proceeded to do a preliminary design of a pneumatic launch assist system. Note that we uncovered an earlier proposal by A. Juhasz (2000) at NASAGRC which utilized a large fan to drive the piston. His system would require design of the fan and the need for real time delivery of large amounts of power, concerns which are not required by the present proposal.

\section{DETAILED DESCRIPTION OF CELT}

The basic design of the CELT system is to use compressed air to push a moving piston down a cylinder. The piston is coupled to the low friction sled riding directly above the cylinder, with the sled carrying the payload RLV(Re-useable Launch Vehicle). Conceptual sketches of the system are shown in Figures 1 and 2.

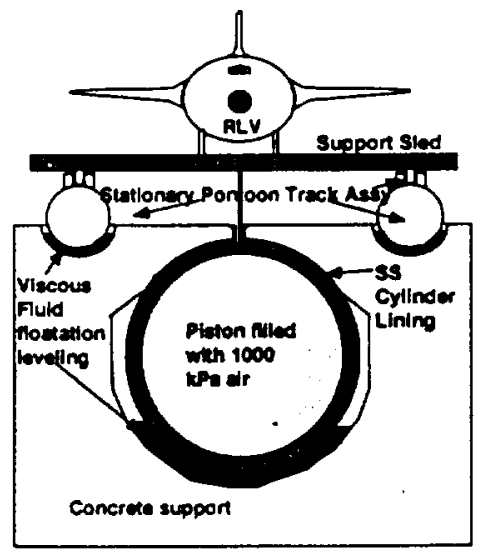

FIGURE 1. Cross-Section View.

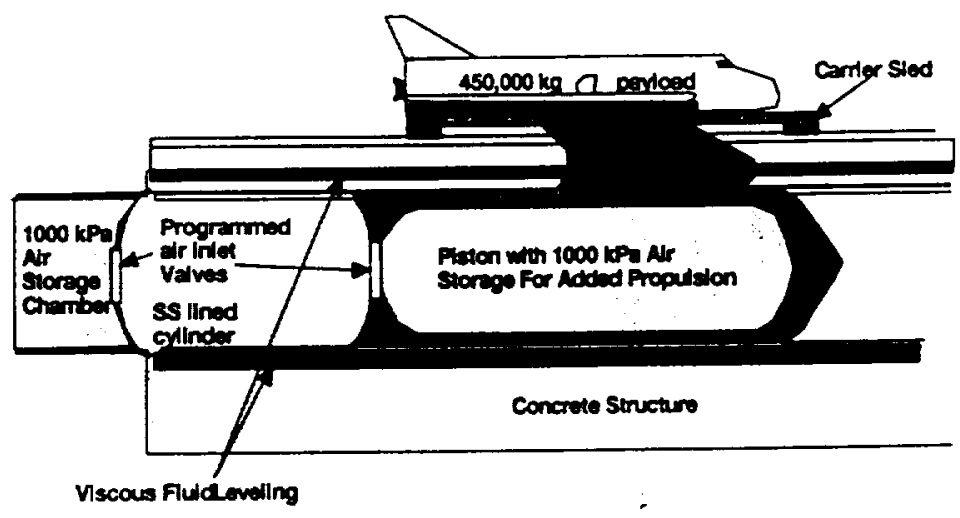

FIGURE 2. Longitudinal Cut-Away View.

The CELT system would be propelled by medium pressure air storage chambers, one at the beginning of the tube and coaxial with it, and the other on the piston. A $9 \mathrm{~m}$ diameter horizontal piston would develop $13 \mathrm{E}+06 \mathrm{~N}$ with a differential pressure of $200 \mathrm{kPa}$, enough to accelerate a $700,000 \mathrm{~kg}$ load at $20 \mathrm{~ms}^{-2}$. The low pressure of the system allows the use of a thin stainless steel liner to provide a smooth surface, while the supporting concrete maintains the cylinder's shape and supports the track and payload. The cylinder gas leakage needs only to be small compared to the gas supply rate. The piston is magnetically or pneumatically levitated within the cylinder to reduce friction and eliminate high speed wheels. Controlled stopping of the CELT system is possible by controlling the build up of gas 
pressure ahead of the piston through programmed valving of the gas exit ports, as shown in Figure 3. A combination of head pressure and vacuum drag will rapidly slow the vehicle without exceeding $20 \mathrm{~ms}^{-2}$. For fail-safe operation, the pressure can be vented at a mid-tube vent, and the valving pre-set for $20 \mathrm{~ms}^{-2}$ stopping before launch, assuming a full vehicle load.

Launch Point

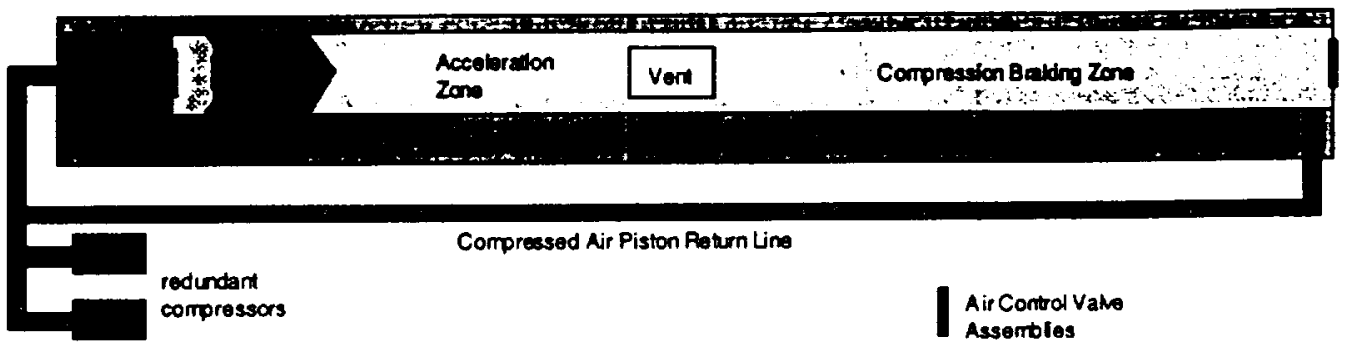

FIGURE 3. CELT System Design Concept.

This would stop an aborted launch with no intervening action by the control system, while stopping the unloaded sled with only moderate $\left(60 \mathrm{~ms}^{-2}\right)$ loads. Return of the piston to the starting position could be accomplished by pumping air to the far end of the tube.

The issue of maintaining an even bed for the track and pneumatic tube are addressed by supporting the pneumatic tube and a stationary pontoon/track assembly in troughs of a viscous fluid. The design of the troughs and cylinders can be such that the cylinders move very little under the weight of the moving load, by forcing the supporting fluid to rise significantly. This same system of support was proposed for high speed pneumatic trains to allow for soil movement beneath sections of track without producing abrupt changes in track elevation (Edwards, 1965).

The relatively thin coupling plate would incorporate a roller bearing coupling to the sled to allow for movement between the sled and piston. This allows the piston and sled to be separately supported on tracks without precise alignment. Sealing of the slot is only required after the piston passes in a non-evacuated system. This can be accomplished by tripping a seal with the link plate, or using the air pressure to move a seal. The relatively thin slot creates a large splitting force on the cylinder. This force is supported by a stiff $U$-channel welded to the liner and anchored in the reinforced concrete.

The use of commercially available parts for the system is an important part in achieving cost and time to install goals. Commercial compressors are available with pumping rates up to $13 \mathrm{~m}^{3} / \mathrm{s}$. Using the redundant design shown in Figure 3 , two such compressors would require 4 hours to fill the storage chambers for launch. The air control valves are available in a $1.2 \mathrm{~m}$ diameter butterfly valve with a pneumatic actuator capable of opening or closing in $0.5 \mathrm{sec}$. These valves have been used on pipelines to control flow and mixing, with millions of cycles without failure. In a $9 \mathrm{~m}$ diameter cylinder head, 12 such valves can be mounted and programmed to deliver the proper flow rate during acceleration and braking. Modification to the stored pressure and valve sequencing would allow adaptation to different loads.

Safety of the CELT system is enhanced by the auto-abort design, the use of $1000 \mathrm{kPa}$ air (no $\mathrm{O} 2$ deficiency), no toxic or hazardous gases, and no exposed electrical ignition sources. The demonstrated high reliability of pneumatic design will be enhanced by redundant controls and fail-safe operational design.

\section{TECHNICAL CHALLENGES}

No launch assist system is without some technical challenges to be studied and overcome. The CELT is no exception, with challenges in the practically achievable velocity, pressure gradients in the cylinder, offset forces between piston and sled, suitability of air cushion support for the piston and sled, and the aerodynamics of the RLV 
on the sled. Some of these issues need to be addressed in the early stages of development to prove feasibility and assess design options. Others will have to accompany the arrival of an RLV design.

\section{DEVELOPMENT STEPS}

Development of the CELT is restrained by the availability of suitable launch vehicles for the second and final stages. The project would progress from a $5 \mathrm{~cm}$ diameter rube for laboratory evaluation and modeling, to a $1 \mathrm{~m}$ tube for a remotely piloted drone, and finally a full scale $9 \mathrm{~m}$ diameter tube and piston for a $450 \mathrm{MT}$ RLV. Some representative sizes of CELT development stages are shown in Table 1.

TABLE 1. Celt System Sizing.

\begin{tabular}{lrrr}
\hline System Attribute & Lab Scale & Drone & RLV \\
\hline System Size $(\mathrm{m})$ & 0.05 & 1.5 & 9 \\
Accelerated Weight $(\mathrm{kg})$ & 20 & 6,000 & 700,000 \\
Tube Length $(\mathrm{km})$ & 0.15 & 0.9 & 6 \\
\hline
\end{tabular}

\section{Lab Scale System}

This $5 \mathrm{~cm}$ diameter system would utilize readily available commercial tubing to construct a $0.15 \mathrm{~km}$ test apparatus. The piston would be instrumented to record acceleration and pressure, and transmit that data during testing. The tube would also be instrumented for pressure and velocity measurements. Results from these experiments would be compared with a theoretical fluid dynamics model to predict pressure gradients in the tube for gas releases from both the tube end and the piston. Experimental data for both ambient pressure tubes and evacuated tubes would be developed and compared with theoretical predictions. After experimental verification of the model, predictions for larger systems would be made and the results examined for feasibility to proceed.

\section{Drone Launch System}

This system would accelerate and launch a remotely piloted drone capable of flight speeds greater than $270 \mathrm{~ms}^{-1}$. One such drone would be the RAM-jet powered D-21, which would be an appropriate model for Gen 2 \& 3 vehicles. The system design would incorporate all engineering and safety features of a full size system, but could be made much shorter by allowing greater acceleration. Decisions on modifications to the drone will drive costs and time. The system might be capable of achieving orbit with a small payload and heavy modifications to the D-21. A simple launch and recovery mechanism would be much less costly. Techniques for welding steel sheet into a smooth interior cylinder would be developed along with piston air cushion support and a suitable sled support system. The latter might be a magnetic levitation track or the more desirable (from a safety standpoint) air cushion support. Costs for the launch assist system would be quite modest compared to the vehicle costs if any significant modifications are done.

\section{Full Size RLV System}

Cost of construction would escalate significantly with the construction of the full size system. With nearly 100 times the weight capacity, concrete costs alone would be $\$ 200 \mathrm{M}$. Despite the size of the undertaking. total costs should be quite reasonable compared with present launch facilities. At present pricing, the compressors and air control valves would total less than $\$ 5 \mathrm{M}$. Utilizing the techniques learned form the drone launch stage, the tube construction should go smoothly. The requirements for a Gen 3 vehicle include a launch assist acceleration that does not exceed $20 \mathrm{~ms}^{-2}$, and smoothly translates to $5 \mathrm{~ms}^{-2}$ at release of the RLV. This launch profile can be achieved by stopping the gas flow into the cylinder, and allowing the acceleration to be completed by adiabatic gas expansion. Such a profile has been constructed, and is shown in Figures 4 and 5 . The time to release from initial start is 19 seconds. 


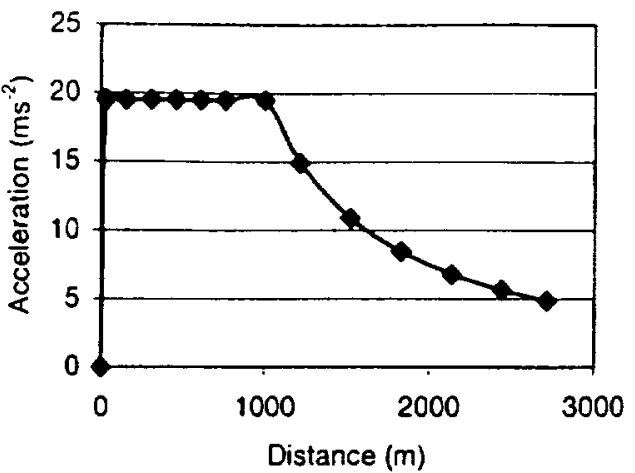

FIGURE 4. Acceleration Profile.

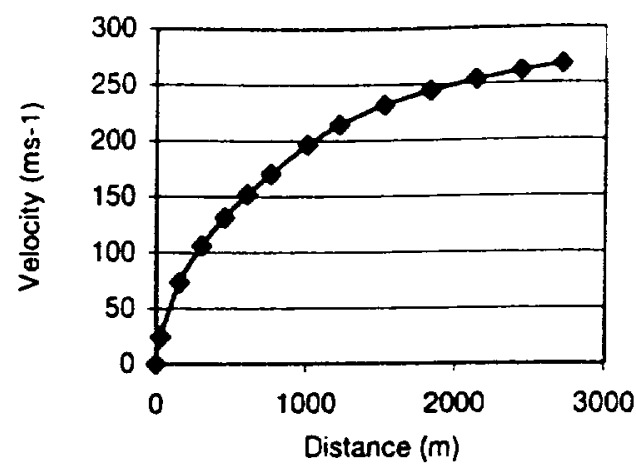

FIGURE 5. Velocity Profile.

\section{CONCLUSIONS}

Pneumatic trains driven by a cylinder with a slot connection to the rail cars were used in Europe in the 1840's. Although they were smooth and quiet, the leather seals on the slot proved to be a maintenance headache, as rats liked to chew on them (Edwards, 1965). If modern materials were available then, we might be riding such trains today! The northeast corridor system was rejected for reasons that do not apply to the present proposal. The ability to develop the forces required for initial acceleration to moderate speeds does not seem to be in question. If we were trying to achieve $180 \mathrm{~ms}^{-1}$, then we would probably already be past TRL (Technical Readiness Level) 6 . The main risk is achieving the $270 \mathrm{~ms}^{-1}$ mark, and there are several ideas for solving this problem, if it occurs. Two prior researchers (Rajan, 1966; Juhasz, 2000) report achieving $350 \mathrm{~ms}^{-1}$ in small pneumatic tube accelerators. Although a pneumatic system is limited to the speed of sound in the propelling gas, it has several advantages over competing technologies. The technology is well developed with components readily available. Pneumatic systems have demonstrated high reliability over many years of industrial applications. Low speed pneumatic transport systems have failure rates below 1 in 4000 , with no system redundancy. They are intrinsically safe with no electrical ignition sources, toxic fumes or oxygen deficiency hazards. We can build a safer system, more quickly and at much lower cost using a pneumatic approach. Lets lower the cost to send payloads to orbit in 10 years, rather than 25 .

\section{REFERENCES}

Edwards. L. K., “High-Speed Tube Transportation," Scientific American, v.213, pp 30-40, Aug, 1965.

Gouse, S. W. and Wali, E. I., "Tube Vehicle Systems: Aerodynamic Characteristics," NTIS Order No. PB-204 933, Final Report, Camegie-Mellon Univ., Transportation Research Institute, Oct 1971.

Hammitt, A. G., "The Aerodynamics of Vehicles in Finite Length Tubes," NTIS Order No. PB-236 692/0, Final report Sep 72-Oct 73, TRW Transportation and Environmental Operations, Redondo Beach, CA, April 1974.

Juhasz, A. J., NASA Glenn Research Center, LeRC 30I-3/(216)433-6134, private communication, 2000.

King. M. and Smylie, I. W., "State-of-the-Art Tube Vehicle System," NTIS Order No. PB-193 273, Final Report, TRW Systems Group, Redondo Beach, June, 1970.

King, M. and Smylie, I. W., "Tube Vehicle System Parametric Investigation," NTIS Order No. PB-193 274, Final Report, TRW Systems Group, Redondo Beach, 15 June, 1970.

Panunzio, S. and Magnus, D. E., “Experimental Investigation of the Near Field for Tube Vehicles," NTIS Order No. PB-198 205, Final report, General Applied Science Labs, Inc, Westbury, NY, Nov 1970.

Rajan, J. R. N. and Kumar, S., "Transient Subsonic Viscous Flow in the Vacuum-Air Propulsion System," NTTS Order No. AD-718 776. Interim Technical Report No S, Army Research Office, Durham, NC, Sept 1966.

Tevepaugh, J. A. and DeJarnette, F. R., "Design of a Hybrid Underground Rapid Transit System (HURTS)." High Speed Ground Transportation Journal, v 9, Nol, pp 321-330, 1975.

Trzaskoma, W. P., "Tube Vehicle System (TVS) Technology Review," NTIS Order No. PB-193 451, Interim Report, 1966-69, Mitre Corp., McLean, VA, July, 1970.

Woodbury, C. A., et al, "An Experimental Investigation of Pneumatic Tube Vehicle Systems," High Speed Ground Transportation Journal, v 8, No3, pp 155-165, 1974. 